\title{
Formação permanente do professorado: novas tendências
}

\section{Permanent professorial training: New Trends}

\author{
Taisson Pedrozo Cogo (taissonpedrozo@ gmail.com) \\ Instituto Federal Farroupilha (IFFAR) - Campus Jaguari. \\ Josete Bitencourt Cardoso (josete.cardoso@iffarroupilha.edu.br) \\ Instituto Federal Farroupilha (IFFAR) - Campus Jaguari. \\ Vantoir Roberto Brancher (vantoir.brancher@iffarroupilha.edu.br) \\ Instituto Federal Farroupilha (IFFAR) - Campus Jaguari.
}

Resumo: Este escrito trata-se de uma resenha crítica do livro Formação Permanente do professorado: Novas tendências, de Francisco Imbernón. Nessa pequena grande obra, composta de doze capítulos podemos observar uma produção que analisa criticamente a atuação docente e a formação permanente de professores. Imbernón tece considerações sobre o processo formativo dos professores, tratando dos mais diversos fatores que influenciam a prática docente, ao mesmo tempo, problematiza os principais obstáculos do fazer pedagógico com intuito de qualificá-lo. Ao resenhar esta obra, através desta sistematização, visamos incentivar/problematizar, quanto à necessidade da formação permanente de professores diante das constantes transformações sociais, culturais, econômicas e comunicativas que se percebem na contemporaneidade.

Palavras-chave: Formação de professores, Formação Permanente de Professores, Trabalho Colaborativo, Aprendizagem Docente.

\begin{abstract}
This writing is a critical review of the book Permanent Formation of the Teacher: New Trends, by Francisco Imbernón. In this small great work, composed of twelve chapters, we can observe a production that critically analyzes the teaching performance and the permanent formation of teachers. In this small great work, composed of twelve chapters, we can observe a production that critically analyzes the teaching performance and the permanent formation of teachers. By reviewing this work, through this systematization, we aim to encourage/problematize, as to the need for permanent teacher training in view of the constant social, cultural, economic and communicative transformations that are perceived in contemporaneity.
\end{abstract}

Keywords: Teacher Training, Permanent Teacher Training, Collaborative Work, Teaching Learning

\section{RESENHA}

Formação permanente do professorado: Novas tendências, é uma obra de autoria de Francisco Imbernón, escritor espanhol Mestre e Doutor em Filosofia e Ciências da Educação. Seu trabalho está centrado na problematização de teorias e práticas 
educativas e formação docente. Desenvolve escritas sobre formação inicial e permanente de professores do ensino básico ao universitário, assim como sobre a formação de profissionais de vários setores, deliberando, inclusive, sobre a própria práxis dos formadores.

Na perspectiva do autor, as intensas mudanças, oriundas da globalização cultural e da comunicação, refletiram/refletem sobre o contexto educacional, fato este, que ocasiona a necessidade de se repensar a formação permanente, deixando de lado a padronização da maioria dos cursos até então praticados.

No primeiro capítulo da obra em análise, o autor salienta que os avanços na formação permanente são recentes, já a preocupação com a formação inicial é antiga. Entretanto, salienta que, em ambas etapas formativas, há uma inquietação por saber como e qual é a melhor forma de se realizá-las. Alerta ainda, sobre a necessidade de arriscar-se em novas perspectivas de atuação, as quais possam colaborar com a construção do futuro, promover inovações e descobrir novas maneiras de ver e interpretar a realidade da educação, preocupação esta, que nasceu nas últimas décadas, em um período de constantes transformações e crises. Outro alerta, é com relação à superação da desmotivação e acomodação dos professores face a um modelo defasado. Daí a necessidade de que os professores se atrevam a buscar outras perspectivas de formação e mudanças conceituais/atitudinais.

No segundo capítulo, o autor fala sobre a repercussão das mudanças sociais na formação permanente do professorado e, por conseguinte, na educação. Nos apresenta elementos que influenciam na educação e na formação, bem como, as repercussões destes na ação docente. Segundo ele, as transformações educativas precisam refletir não só na aprendizagem dos alunos e no sistema educativo, mas também, gerar benefícios na formação e no desenvolvimento profissional dos professores.

O capítulo três, o qual trata da formação permanente, os professores necessitam olhar para si mesmos e ao seu entorno de forma reflexiva e questionadora. Essa observação precisa ocorrer em um clima de colaboração, exige uma organização que permita a participação no planejamento e avaliação dos resultados da formação. Desta forma, inserindo-se no processo formativo/autoformativo o professor se sentirá valorizado e reconhecerá as transformações individuais e coletivas resultantes da 
formação. Aponta ainda, para a importância da ajuda entre os pares através de observação e devolutiva entre colegas. Imbernón (2009, p. 28) relata que, “Ter o ponto de vista de outro oferece ao docente uma perspectiva diferente de como ele ou ela atua com os estudantes", contribuindo assim, com o crescimento do professor e favorecendo mudanças em suas estratégias educativas. Para que isso aconteça, o individualismo tem que ser deixado de lado, é preciso estarmos abertos às considerações e às mudanças que por vezes se fazem necessárias.

No quarto capítulo, o autor referenda os principais obstáculos que podem se transformar em limitadores para a formação. Já no capítulo cinco, Imbernón inicia fazendo uma crítica sobre a proporcionalidade da formação existente e as poucas mudanças que promovem nas ações cotidianas dos professores, e também ao predomínio de uma formação transmissora e uniforme com pouco impacto no processo de ensino realizado.

Segundo o autor do livro, a formação requer que as ações partam dos problemas que circundam as instituições escolares. Além disso, a formação precisa estar acompanhada de mudanças contextuais, trabalhistas, de carreira e de salários, aspectos estes, que precisam ser pensados ao rever os processos de formação de maneira a despertar o desejo dos professores em qualificar-se. Quando os professores assumem sua formação, eles se tornam protagonistas deste fazer, uma vez que estão partindo de dentro do contexto social e profissional e assumindo uma perspectiva crítica em educação e formação. Abandonam assim, a enganosa convicção de escola neutra rumo à construção de uma postura mais politizada, baseada na perspectiva de educação libertadora. Imbernón (2009) relata ainda que, "Uma forma de combater esse isolamento e individualismo [...] é a formação colaborativa[...]” (IMBERNÓN, 2009, p. 65). Desta forma, deixa-se para trás o individualismo e o conservadorismo, o que nos possibilita alcançar resultados mais frutíferos na formação permanente, na qualidade da educação e dos fazeres coletivos.

O capítulo seis traz críticas ao modelo de formação permanente, que por sua vez, pretende solucionar os problemas de diversos contextos educativos. Descortina uma formação que não responde às peculiaridades locais tornando-se ineficaz. Diante disso, se faz necessário gerar alternativas a esse tipo de formação, que comumente é 
desenvolvida como se fosse uma sessão de treinamento, solucionadora de problemas genéricos. Uma delas, segundo o autor, seria propor modelos que se aproximem das situações problemas e do contexto onde se dá os processos de ensino. A formação baseada em problemas da escola atende as necessidades reais dos professores. Nessa perspectiva de trabalho, abandona-se a formação enquanto treinamento e, passa-se a organizá-la a partir de projetos ou "pesquisas-ações", nas quais a escola ou os espaços educativos passam a ser o foco dos mesmos.

No sétimo capítulo, o autor faz referência ao individualismo dos professores ou da cultura docente. A partir disso, problematiza a necessidade do ensino ser pensado pela coletividade para melhorar a atuação do professorado, a organização das instituições educativas e a aprendizagem dos alunos.

O individualismo, na perspectiva do autor, difere de individualidade, sendo esta, necessária para a análise e reflexão sobre a própria prática. Logo, para que seja possível desenvolver a colaboração, faz-se necessário romper com o individualismo, realizando uma formação responsável e comprometida com metas coletivas. Além disso, promover uma formação permanente, implica uma metodologia sistemática de trabalho e um clima afetivo colaborativo. Só assim, será possível o desenvolvimento de verdadeiras transformações positivas no ambiente educacional. O capítulo relata ainda, que, em uma formação colaborativa, é preciso dar-se interação e intercâmbio de ideias entre o coletivo docente. Destaca a importância da comunicação entre os colegas para a superação do individualismo e o desenvolvimento formativo pessoal e profissional.

Na sequência, o capítulo oito expressa a importância do professor deixar de ser objeto das decisões sobre a própria formação. Assumindo-se, em contrapartida, como sujeito na tomada de decisões que orientam tanto os rumos da formação, quanto das atividades profissionais. A formação pensada pelos próprios professores auxilia a mudar e/ou potencializar a identidade docente. Porém, somente isso, não é o suficiente, se faz necessário também, o desenvolvimento profissional, composto por um conjunto de fatores como: salário, carreira, estruturas, legislação trabalhista, entre outros elementos que também são fundamentais para a conquista identitária docente.

No nono capítulo do livro, o autor esclarece que, sem ajuda dos sujeitos que envolvem as instituições escolares, é difícil de superar os entraves formativos. Relata 
ainda, que as comunidades formativas podem oportunizar diversos benefícios ao grupo de professores como: compartilhamento de aprendizagens, troca de informações, construção de cultura própria ao grupo, etc. Trabalhar a formação, por meio de comunidades formativas, permite melhorias na organização educativa e para todos os membros da comunidade escolar.

O capítulo dez comenta que a mudança que se pede ao professorado não é simples, assim como ensinar também não é. Tal fenômeno, se intensifica ainda mais na atualidade onde as incertezas e mudanças são intensas e constantes, introduzindo dificuldades específicas ao trabalho docente.

Nos últimos anos, tem predominado o desenvolvimento de ações de formação docente baseadas na racionalidade técnica, qual seja, aquela que não tem pensado nos fenômenos sociais, bem como na complexidade necessária para o desenvolvimento de um ensino de qualidade. Devido a isso, é preciso promover uma formação que facilite a reflexão sobre o próprio fazer, tornando possível compreender e elucidar a complexidade em que se vive e que envolve a prática educativa.

O décimo primeiro capítulo aborda sobre a desmotivação e baixa autoestima do professorado, devido à desvalorização e às condições precárias para o exercício da profissão. Segundo o autor, o limite entre o pessoal e o profissional vem diminuindo e a formação atitudinal ajudaria a melhorar o desenvolvimento pessoal e também as relações interpessoais do professorado. Além disso, essa formação necessitaria transcender os problemas gerais, ajudando a estabelecer vínculos afetivos entre os colegas de profissão o que desenvolveria a auto estima docente.

No último capítulo, coloca-se em discussão a estrutura organizativa da formação permanente e o papel dos formadores. Nele, o autor critica os cursos de "atualização" até então promovidos, os quais reproduziam soluções que servem para todos os contextos. Numa perspectiva de mudança, o formador deve atuar como um colaborador no diagnóstico dos problemas, ajudando a pensar o que e como se faz. Já as atividades formativas, devem possibilitar maior participação dos professores, aproximar-se das instituições educativas, ser mais flexíveis e descentralizadas, ou seja, um modelo reflexivo no qual o professorado se assuma como agente da própria formação. 
A obra faz importantes considerações sobre o processo formativo dos professores, além de permitir reflexões e considerações com relação à necessidade de aperfeiçoamento da formação permanente diante das constantes transformações sociais, culturais, econômicas e comunicativas que vivenciamos. Sua leitura e reflexão é de suma importância no sentido de almejarmos uma formação mais qualificada, que alcance melhorias no fazer do próprio professorado e que possa qualificar a educação.

Através da obra, é possível reconhecer os docentes como agentes fundamentais, ativos e transformadores da organização educacional. Um professorado motivado, qualificado, ciente do seu papel na escola e na sociedade é capaz de, através de suas práticas, desenvolver um ensino de melhor qualidade. Desta forma, sua atuação se dará de maneira transformadora para a comunidade que envolve a instituição.

Assim, concluímos nosso texto destacando que a leitura deste livro é recomendada para todos aqueles sujeitos preocupados com a formação/qualificação dos professores. Indicamos, especialmente, a professores que desejam realizar um trabalho reflexivo e transformador em sua sala de aula, em sua escola ou nos contextos de sua atuação. Trata-se de uma obra que discute os mais diferentes fatores que influenciam a prática docente, apontando alguns rumos sobre formação permanente, permitindo, desta forma, que os professores reflitam acerca da sua profissão, bem como as maneiras de atuar, buscando subsídios para qualificar sua atividade fim, qual seja, o processo de ensino na contemporaneidade.

\section{REFERÊNCIA:}

IMBERNÓN, F. Formação permanente do professorado: Novas tendências. $1^{\circ}$ ed. São Paulo: Ed. Cortez, 2009. 